\title{
Constructing Taipei City Sports Centre Performance Evaluation Model with Fuzzy MCDM Approach Based on Views of Managers
}

\author{
Chen-Yang Wang, ${ }^{1}$ Pei-Hsuan Tsai, ${ }^{1}$ and Hu Zheng ${ }^{2}$ \\ ${ }^{1}$ Department of Business Administration, National Taiwan University of Science and Technology, No. 43, Section 4, Keelung Road, \\ Taipei 106, Taiwan \\ ${ }^{2}$ Graduate Institute Sport Coaching Science, Chinese Culture University, No. 55, Hwa-Kung Road, Taipei 111, Taiwan
}

Correspondence should be addressed to Pei-Hsuan Tsai; pei.hsuan0616@gmail.com

Received 17 September 2013; Revised 23 November 2013; Accepted 24 November 2013

Academic Editor: Kim-Hua Tan

Copyright (c) 2013 Chen-Yang Wang et al. This is an open access article distributed under the Creative Commons Attribution License, which permits unrestricted use, distribution, and reproduction in any medium, provided the original work is properly cited.

This study aims to utilize the fuzzy analytical/network process (FAHP/FANP) and decision-making trial and evaluation laboratory (DEMATEL) approach to recognize the influential indicators of sport centre business management in Taipei city's sports centre. Twenty-three of sports centres with six-dimensions were identified from the literature review and interview with twelve experts (academic and practical experience). By considering the interrelationships among the indices, DEMATEL was used to deal with the importance and causal relationships among the evaluation indices of sports centre. Then, we employ the FAHP/FANP to determine the weight of each management criterion. Our empirical results provide two main insights: first, sports centre business management strategies comprise six-dimensions and 23 indexes; second, the FANP analysis shows that the six key factors are (in order of priority) service price, site conditions, operations management, traffic conditions, sports products, and staff quality. This study uses the FANP and DEMATEL along with mathematical computing in order to provide sports centre managers with a reliable decision-making reference and to assist them in formulating the most effective business strategy possible.

\section{Introduction}

Taiwan has seen rapid economic growth recently, with its gross national income reaching US $\$ 17,590$. The Taiwanese have switched to two-day weekends and are becoming more health conscious; they are also eager to pursue leisure activities. Taiwan's government is attempting to provide a variety of leisure activities suitable for all ages, genders, habits, employment backgrounds, and physical abilities. The government is promoting sports in order to help people switch from an indoor to an outdoor lifestyle and acquire a lifetime sport habit. Because of the increasing demand for leisure activities, Taiwan's current number of public leisure facilities has become inadequate. Therefore, Taipei needs more public sports centres to enable the Taiwanese to more easily attend sports activities, perform community service, pursue lifetime learning courses, and enjoy artistic activities. The vision of
Taiwan's government is to implement "sports anytime, sports anywhere, and sports for everybody" in its capital, Taipei. However, Taipei's government has frozen hiring and budgets and has thus had to use an operate-transfer (OT) strategy, by which nongovernment organizations are called on to manage the centres. The selected nongovernment organizations must support a variety of sports activities, courses, exhibitions, and community programs in the sports centres while helping city residents improve their health and quality of life.

According to the Department of Sports and Taipei's statistical data, Taipei transferred 12 sport centres to nongovernmental organizations from 2003 to 2012. The usage of the centres increased each year, reaching a record high in 2011 with 12,000,000 person-times, indicating that Taipei residents enjoy accessing the centres' leisure activities and that the government's goal matched the people's requirements. As market competitors have now emerged, sports centre performance 
and management are top priority for each of Taiwan's 12 administrative areas. This study's objective is to identify the indicators that can help sports centre managers formulate an ideal management strategy and derive profits.

The analytic hierarchy/network process (AHP/ANP) is a well-known multicriteria decision-making (MCDM) technique widely used in sport management, business, economics, and industry [1-7]. A decision method, AHP/ANP dissects a complex MCDM problem into a hierarchy/network of more easily comprehended subproblems $[1,8-10]$. It is also a measurement theory that prioritizes the hierarchy/network and consistency of judgmental data provided by a group of decision makers [10-13]. Human judgment about preferences is often unclear and difficult to estimate using exact numerical values, and fuzzy logic is a necessity when handing problems characterized by vagueness and imprecision. Therefore, this study combines fuzzy set theory with AHP/ANP in a sports centre performance model [14-17].

The hybrid sports centre performance evaluation model presented in this study structures the problem of evaluating 23 indices for sports centre performance in a fuzzy hierarchical/network form and links the determinants, dimensions, and enablers of performance with the various indices. This study aims to use indicators from the relevant literature and expert questionnaires to construct a successful sports centre management strategy. The indicator analysis combines qualitative and quantitative data. In this study also decisionmaking trial and evaluation laboratory (DEMATEL) method [18] is used to extract the mutual relationships of interdependencies within criteria and the strength of interdependence. Moreover, through FAHP/FANP analysis, the study guides the construction of a sport centre management evaluation model. The analysis data can also assist professional sport centre managers with their resource allocation and marketing plans.

The rest of this study is organized as follows. In Section 2, we review the application of MCDM to sports management. In Section 3, we present the DEMATEL method, FAHP/FANP evaluation model. In Section 4, we conduct an empirical study. We then provide our concluding remarks in the final section.

\section{Review of MCDM Methods in Sports Management}

This section briefly reviews the previous research on sports management via MCDM [1-3, 9, 19]. Sports management is a branch of sports sciences-the investigation of the techniques, operation, and foundational elements of the management of sports [20-22]. This section reviews the MCDM methods used by previous studies (i.e., [5, 6, 23, 24] in their discussion of sports management performance).

Sinuany-Stern [25] applied the AHP to predict the ranking of the 16 soccer teams of the Israeli National League. Lanoue and Revetta [26] analysed the overall offensive performance of major league baseball players by combining the AHP and the players' offensive statistics (i.e., batting averages, runs, doubles, triples, home runs, runs batted in, stolen bases, and walks). Lee and Walsh [23] employed a hybrid strengths, weaknesses, opportunities, and threats (SWOT) and AHP model to identify the decision-making factors that intercollegiate sports administrators employ when determining if they should outsource their sports marketing functions; their results indicate that the decision makers considered strengths or the potentially positive outcomes to be more important than weaknesses, opportunities, and threats. Lee and Ross [24] used the AHP to identify the decision-making factors in global sports sponsorship. The AHP's local weights showed that sports team factors were far more important in decision-making than the country or environment factors, while the AHP's global weights showed that media exposure opportunity was the most influential factor, followed by sponsorship fit, team image, and fan-based strength.

Gou [27] applied the fuzzy system to construct a fuzzy control model for athletic sports; this study focused on ping pong to research the fuzzy control model in athlete sport and selected only a few of its tactics and strategies. Liao and Chang [28] used the MCDM and the analytic network process (ANP) to analyse how Taiwanese TV companies selected their sportscasters for the Olympic Games. The researchers interviewed 18 senior executives and found that the companies' selection criteria were interrelated. Unlike earlier researchers, who had ignored this interdependence among factors, the authors applied a more feasible and accurate approach, the ANP, which captured the criteria's dependent relationships. Chen [29] created a hybrid MCDM model combining decisionmaking trial and evaluation laboratory (DEMATEL) and ANP methods and applied it to recreation sports in order to identify ways of enhancing recreational sports participation and improving educators' abilities. The author found that the external environment was the most important dimension and that, among seven evaluation criteria, "psychology" was the most important consideration when planning a recreational sports program, followed by "entertainment."

Thus, a review of the literature on the measurement of sports management clearly shows that various MCDM methods can be applied in this field (sport management). In the literature, there is few using DEMATEL method with FANP aimed at evaluating the performances of sport management [29]. Therefore, the main purpose of this study is to construct a hybrid evaluation model (using DEMATEL and FANP) (the aim of this study is to construct a network hierarchical feedback system based on the DEMATEL method to address the complex interdependent relationships among the variables and thereby construct a relation structure among the measurement indicators for evaluating sports centre performance. The ANP is used to evaluate the measurement indicators for sports centre performance) based on the proposed framework for the sports centre in Taipei. A MCDM method is proposed for this purpose, as such a method makes the performance evaluation more flexible and informative than do the traditional methods (i.e., statistics analysis). 


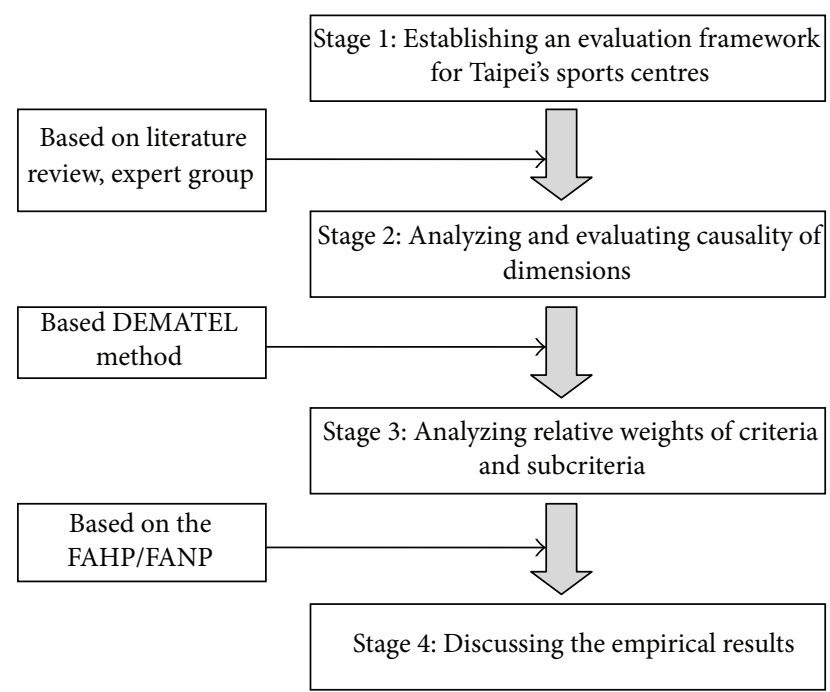

FIgURE 1: Proposed evaluation model of Taipei's sports centres.

\section{Decision-Making Model and Analytical Methods}

Following our review of the relevant literature and based on discussions with both professional and academic sports management experts, some of the most important selection criteria for sports centre operations can be identified. Our evaluation procedure consists of several steps, as shown in Figure 1. After the criteria framework is constructed, adequate sports centre performance evaluation indicators have been selected and then utilizing the DEMATEL and FANP, respectively, further establishes the causality between the six perspectives (i.e., service prices, site conditions, staff qualify, sports products, traffic conditions, and operations management) as well as the relative weights between evaluation indicators. [30-33]. The subsections below provide a detailed description of each step of the evaluation process.

\subsection{Determination of the Group of Experts for the Sports Cen-} tre. Twelve professional and academic experts were selected. Since the important weights for both types of experts are considered to be equal, to avoid the occurrence of bias, all experts consulted in this study had both academic and practical experience and met the following conditions: (a) they held a managerial position in either a sport club or sport management company; (b) they had research backgrounds related to sports management.

The participating experts comprised eight managers (working in either the sports centre or a sports club) and four academics (whose principal research area was sports management). Background information about these experts is presented in Table 1 .

\subsection{Construction of an Evaluation Model and Defining the} Evaluation Criteria. From the six perspectives (i.e., service prices, place conditions, staff qualify, sports products, traffic conditions, and operations management) and based on our
TABLE 1: Background information of sports center experts.

\begin{tabular}{lc}
\hline Category/classification & Number \\
\hline Working background & \\
Industry field & 8 \\
Academia & 4 \\
Education level & \\
Bachelor & 3 \\
Master & 5 \\
Ph.D. & 4 \\
Work classification & \\
Sports centre & 5 \\
Sports club & 3 \\
Scholars & 4 \\
\hline
\end{tabular}

review of the literature, 45 evaluation indexes for sports centre performance were summarized. Then, expert questionnaires were used to screen the indexes' fit for the sports centre performance evaluation. Twenty-three evaluation indexes were selected by the committee of experts (i.e., the group of twelve comprising professionals and academics). The criteria for the sports centre performance evaluation are described in Table 2. The hierarchical framework for the six sports centre evaluation criteria (i.e., six dimensions and 23 indices) is shown in Figure 2. The 23 evaluation indices are grouped into six dimensions: $\mathrm{SP}$ : service prices $\left(\mathrm{SP}_{1}-\mathrm{SP}_{4}\right), \mathrm{SC}$ : site conditions $\left(\mathrm{SC}_{1}-\mathrm{SC}_{4}\right), \mathrm{SQ}$ : staff qualifies $\left(\mathrm{SQ}_{1}-\mathrm{SQ}_{3}\right), \mathrm{SD}$ : sport products $\left(\mathrm{SD}_{1}-\mathrm{SD}_{4}\right), \mathrm{TC}$ : traffic conditions $\left(\mathrm{TC}_{1}-\mathrm{TC}_{4}\right)$, and $\mathrm{OM}$ : operations management $\left(\mathrm{OM}_{1}-\mathrm{OM}_{4}\right)$.

3.3. Analyzing and Evaluating Causality of Dimensions with DEMATEL. The experts who have practical experience of extension education have been consulted (as shown in Table 1) and conducted mutual direct influence evaluation aiming at each evaluation dimensions (SP, SC, SQ, SD, TC, and $\mathrm{OM}$ ). Evaluation indicators are divided into five degrees and numbers from 0 to 4 to represent different extents [3]. Then DEMATEL is used to derive a total-relation matrix of six evaluation dimensions for unravelling causal relationships among indices and the related steps are shown below. (The procedure of DEMATEL is summarized as follows based on $[3,34]$.)

Step 1 (defining elements and determining relations). Through studying a literature review or brainstorming, inducting and defining the elements of the systems and then the relation between elements are judged by professionals subjectively via the design of questionnaires. The professional questionnaire is based on comparing criteria form of each pair of elements and it is represented by numbers from 0 to 4 to present "no influence" to "very high influence."

Step 2 (setting up direct-relation matrix). After comparing the influential degree between one element and another, an $n \times n$ matrix could be obtained. The direct-relation matrix is shown in (1) and is presented with $\mathbf{A}$. The numbers inside the matrix present the influential extent between elements. 


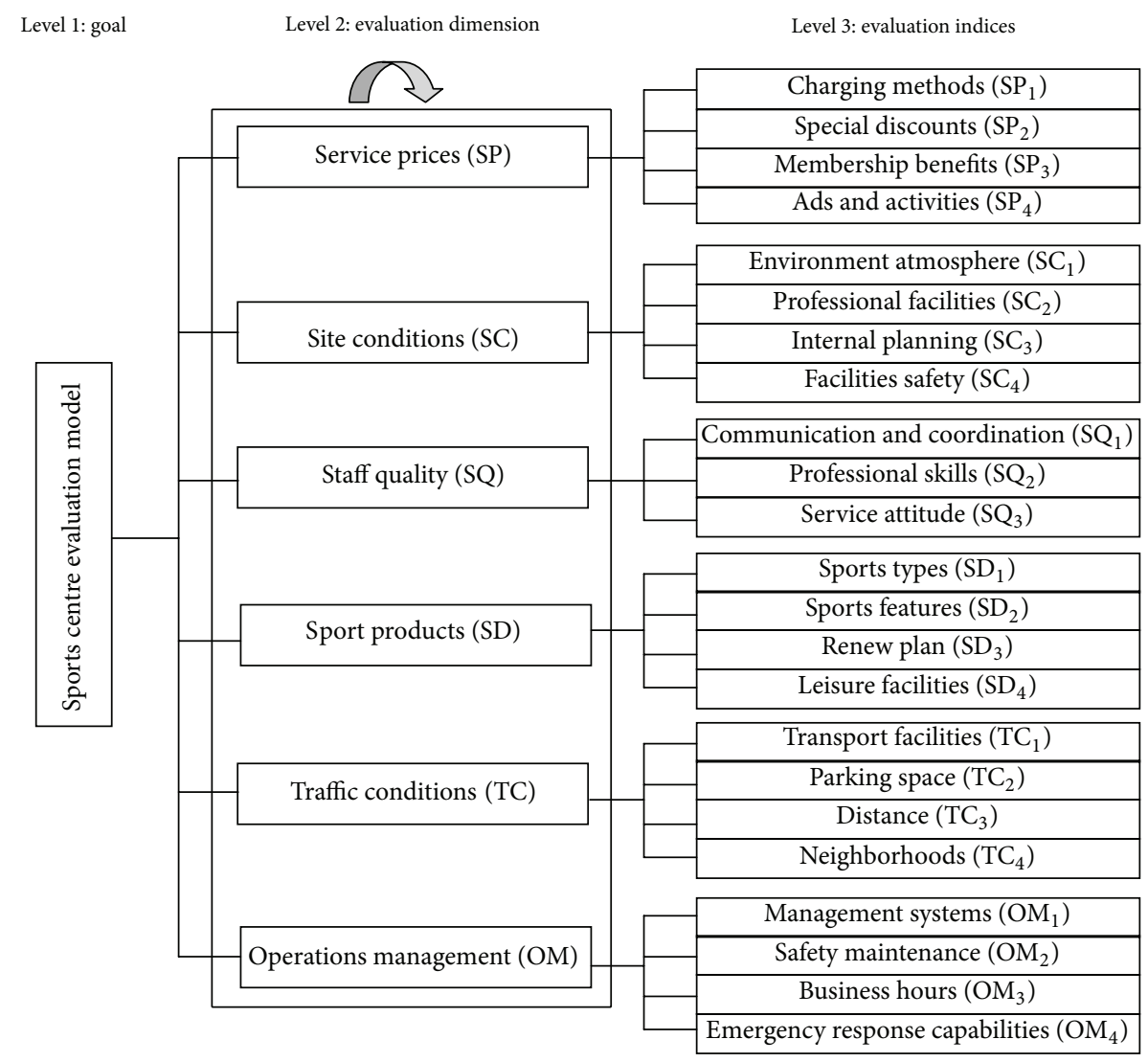

FIgURE 2: Hierarchal evaluation structure of sports centre.

Consider

$$
\mathbf{A}=\left[\begin{array}{lll}
a_{11} & a_{12} & a_{13} \\
a_{21} & a_{22} & a_{23} \\
a_{31} & a_{32} & a_{33}
\end{array}\right]
$$

Step 3 (computing normalized direct-relation matrix). Make

$$
S=\frac{1}{\max _{1 \leq i \leq n}\left(\sum_{j=1}^{n} Z_{i j}\right)},
$$

and then multiply the elements of direct-relation matrix (A) by $\mathbf{S}$, which derives standardized direct-relation matrix (D) as

$$
\mathbf{D}=\mathbf{S} \times \mathbf{A}
$$

Step 4 (computing total-relation (direct/indirect) matrix). Using $\mathbf{T}$ to represent a total-relation matrix, I as a unit matrix, $\mathbf{D}$ as a total-relation matrix, and $\mathbf{D}=\left[d_{i j}\right]_{n \times n}, \lim _{k \rightarrow \infty}\left(\mathbf{D}^{2}+\right.$ $\left.\cdots+\mathrm{D}^{k}\right)$ means that it is an indirect matrix. When $0 \leq d_{i j}<1$, then $\lim _{k \rightarrow \infty} d^{k}=0 . \mathbf{T}=\lim _{k \rightarrow \infty}\left(\mathbf{D}+\mathbf{D}^{2}+\cdots+\mathbf{D}^{k}\right)=$ $\lim _{k \rightarrow \infty} \mathbf{D}\left(\mathbf{I}+\mathbf{D}^{2}+\cdots+\mathbf{D}^{k-1}\right)$ and $\mathbf{T}=\mathbf{D}(\mathbf{I}-\mathbf{D})^{-1}, \mathbf{T}=\left[t_{i j}\right]$, $i, j \in\{1,2, \ldots, n\}$.

Step 5 (drawing causal diagram and result analysis). The total amount of each row is presented by $D_{i}$ and the total amount of each column is presented by $R_{j}$.
Consider

$$
\begin{aligned}
& D_{i}=\sum_{j=1}^{n} t_{i j}, \quad i=1,2, \ldots, n, \\
& R_{j}=\sum_{i=1}^{n} t_{i j}, \quad j=1,2, \ldots, n .
\end{aligned}
$$

The casual diagram uses $(D+R, D-R)$ as ordered pairs. The horizontal axis $(D+R)$ presents the influential degrees of relations between elements; however, vertical axis $(D-R)$ represents the influential degrees of relations between one element and other elements. Therefore, the sophisticated causality of elements themselves could be observed as a simple and explicit structure by the causal diagram. The structure could be used as a guide of counsel or strategy against problems made up by decision makers or managers.

3.4. Using FAHP/FANP to Evaluate the Sports Centre Performance. The fuzzy set theory, introduced by Zadeh [35], is appropriate for dealing with informational uncertainty and imprecision. It is a valuable tool for measuring the ambiguity of concepts associated with human beings' subjective judgments, which are often vague. One of the easier ways to clarify these subjective judgments is through linguistic variables, which are very useful in dealing with situations that 
TABLE 2: Descriptions of the evaluation indices for sports centre.

\begin{tabular}{|c|c|c|}
\hline Evaluation criteria & Evaluation subcriteria & Descriptions \\
\hline \multirow{4}{*}{ Service prices (SP) } & Charging methods $\left(\mathrm{SP}_{1}\right)$ & $\begin{array}{l}\text { Charge by times, monthly, quarterly, and yearly membership fee } \\
\text { for courses and facilities rental. }\end{array}$ \\
\hline & Special discounts $\left(\mathrm{SP}_{2}\right)$ & $\begin{array}{l}\text { Occasional marketing projects like coupons, free gifts, and } \\
\text { anniversary discount for consumers. }\end{array}$ \\
\hline & Membership benefits $\left(\mathrm{SP}_{3}\right)$ & $\begin{array}{l}\text { Members have birthday coupons, personal lockers, member } \\
\text { publications, and free fitness coach lessons. }\end{array}$ \\
\hline & Ads and activities $\left(\mathrm{SP}_{4}\right)$ & $\begin{array}{l}\text { Sports centre ads for sport games competition, public service } \\
\text { activities, and health advocacy to match consumers' needs and } \\
\text { attention. }\end{array}$ \\
\hline \multirow{4}{*}{ Site conditions (SC) } & Environment atmosphere $\left(\mathrm{SC}_{1}\right)$ & Sport centre creates health and sport atmosphere. \\
\hline & Professional facilities $\left(\mathrm{SC}_{2}\right)$ & Complete sports facilities and equipment. \\
\hline & Internal planning $\left(\mathrm{SC}_{3}\right)$ & Different sport facilities plan for suitable space. \\
\hline & Facilities safety $\left(\mathrm{SC}_{4}\right)$ & $\begin{array}{l}\text { Regular facility safety inspection and monitoring of facility } \\
\text { installations according to legal instructions. }\end{array}$ \\
\hline \multirow{3}{*}{ Staff qualifies (SQ) } & $\begin{array}{l}\text { Communication and } \\
\text { coordination }\left(\mathrm{SQ}_{1}\right)\end{array}$ & $\begin{array}{l}\text { Staff should service and communicate with consumers quickly and } \\
\text { correctly. }\end{array}$ \\
\hline & Professional skills $\left(\mathrm{SQ}_{2}\right)$ & Coach should have professional knowledge and instruction skills. \\
\hline & Service attitude $\left(\mathrm{SQ}_{3}\right)$ & $\begin{array}{l}\text { Service staff (not including coach) should properly handle } \\
\text { consumers' complaints and provide best service satisfaction. }\end{array}$ \\
\hline \multirow{4}{*}{ Sport products $(\mathrm{SD})$} & Sports types $\left(\mathrm{SD}_{1}\right)$ & Sport centre can provide sports type. \\
\hline & Sports features $\left(\mathrm{SD}_{2}\right)$ & Sport centre facilities have special features and attractions. \\
\hline & Renew plan $\left(\mathrm{SD}_{3}\right)$ & Sport centre facilities and lessons are periodically renewed. \\
\hline & Leisure facilities $\left(\mathrm{SD}_{4}\right)$ & $\begin{array}{l}\text { Sport centre has leisure facilities such as a coffee shop, convenient } \\
\text { store, message service, and kids' playground. }\end{array}$ \\
\hline \multirow{4}{*}{ Traffic conditions (TC) } & Transport facilities $\left(\mathrm{TC}_{1}\right)$ & $\begin{array}{l}\text { Sport centre location can be reached by multiple public } \\
\text { transportation modes. }\end{array}$ \\
\hline & Parking space $\left(\mathrm{TC}_{2}\right)$ & Plenty of parking space for customers' cars and motorcycles. \\
\hline & Distance $\left(\mathrm{TC}_{3}\right)$ & $\begin{array}{l}\text { The distance between customers' homes or work places to sports } \\
\text { centre. }\end{array}$ \\
\hline & Neighbourhoods $\left(\mathrm{TC}_{4}\right)$ & Sports centre is convenient to most neighbourhoods. \\
\hline \multirow{4}{*}{$\begin{array}{l}\text { Operations management } \\
(\mathrm{OM})\end{array}$} & Management systems $\left(\mathrm{QM}_{1}\right)$ & $\begin{array}{l}\text { Financial and operational departments have effective management } \\
\text { systems to prevent financial crises or downtimes. }\end{array}$ \\
\hline & Safety maintenance $\left(\mathrm{QM}_{2}\right)$ & $\begin{array}{l}\text { Consumers' safety should be the first priority of centre } \\
\text { management. }\end{array}$ \\
\hline & Business hours $\left(\mathrm{QM}_{3}\right)$ & Daily business hours from daytime (open) to night time (close). \\
\hline & $\begin{array}{l}\text { Emergency response capabilities } \\
\left(\mathrm{QM}_{4}\right)\end{array}$ & $\begin{array}{l}\text { Proper handling of emergency issues and regular emergency } \\
\text { response practice. }\end{array}$ \\
\hline
\end{tabular}

are too complex or ill-defined to be reasonably described by conventional quantitative expressions [36].

The AHP, first proposed by Saaty [8], constructs a hierarchical structure for complex problems. The AHP is widely used for tackling MCDM problems in real situations, such as sports management [23, 24], banking performance [1$3]$, manufacturing $[37,38]$, and project evaluations $[39,40]$. Although the traditional AHP can handle expert opinion and provide an evaluation based on multicriteria, it is not fully capable of reflecting human judgments since it uses exact numerical values in pairwise comparison matrices. Therefore, the fuzzy analytic hierarchy process (FAHP) is more appropriate and effective than conventional AHP in an uncertain pairwise comparison environment $[14,15,17]$.
This study obtained the local weights of the sports centre performance indicators by using Chang's [41, 42] extent FAHP method because of its computational easiness and efficiency. Let $X=\left\{x_{1}, x_{2}, \ldots, x_{n}\right\}$ be an object set and let $U=\left\{u_{1}, u_{2}, \ldots, u_{m}\right\}$ be a goal set. In this method, each object is taken, and extent analysis values for each object can be obtained with the following signs:

$$
M_{g i}^{1}, M_{g i}^{2}, \ldots, M_{g i}^{m}, \quad i=1,2, \ldots, n,
$$

where all the $M_{g i}^{j}(j=1,2, \ldots, m)$ are triangular fuzzy numbers (TFNs). The steps of Chang's [41, 42] extent analysis are described below. 
Step 1. The value of the fuzzy synthetic extent with respect to the $i$ th object is defined as

$$
S_{i}=\sum_{j=1}^{m} M_{g i}^{j} \otimes\left[\sum_{i=1}^{n} \sum_{j=1}^{m} M_{g i}^{j}\right]^{-1} .
$$

To obtain $\sum_{j=i}^{m} M_{g i}^{j}$, we performed the fuzzy addition operation of $m$ extent analysis values for a particular matrix as in (7):

$$
\sum_{j=i}^{m} M_{g i}^{j}=\left(\sum_{j=1}^{m} l_{j}, \sum_{j=1}^{m} m_{j}, \sum_{j=1}^{m} u_{j}\right),
$$

and to obtain $\left[\sum_{i=1}^{n} \sum_{j=1}^{m} M_{g i}^{j}\right]^{-1}$, the fuzzy addition operation of $M_{g i}^{j}(j=1,2, \ldots, m)$ values is performed as

$$
\sum_{i=1}^{n} \sum_{j=1}^{m} M_{g i}^{j}=\left(\sum_{i=1}^{n} l_{i}, \sum_{i=1}^{n} m_{i}, \sum_{i=1}^{n} u_{i}\right)
$$

and then the inverse of the vector above is computed as

$$
\left[\sum_{i=1}^{n} \sum_{j=1}^{m} M_{g i}^{j}\right]^{-1}=\left(\frac{1}{\sum_{i=1}^{n} u_{i}}, \frac{1}{\sum_{i=1}^{n} m_{i}}, \frac{1}{\sum_{i=1}^{n} l_{i}}\right) .
$$

Step 2. As $M_{1}$ and $M_{2}$ are two triangular fuzzy numbers, the degree of possibility of $M_{2}=\left(l_{2}, m_{2}, u_{2}\right) \geq M_{1}\left(l_{1}, m_{1}, u_{1}\right)$ is defined as

$$
V\left(M_{2} \geq M_{1}\right)=\sup _{y \geq x}\left[\min \left(\mu_{M_{1}}(x), \mu_{M_{2}}(y)\right)\right],
$$

and can be equivalently expressed as follows:

$$
\begin{aligned}
V\left(M_{2}\right. & \left.\geq M_{1}\right) \\
= & \operatorname{hgt}\left(M_{1} \cup M_{2}\right)=\mu_{M_{2}}(d)=\mu(d) \\
& = \begin{cases}1, & \text { if } m_{2} \geq m_{1}, \\
0, & \text { if } l_{1} \geq u_{2}, \\
\frac{l_{1}-u_{2}}{\left(m_{2}-u_{2}\right)-\left(m_{1}-l_{1}\right)}, & \text { otherwise, }\end{cases}
\end{aligned}
$$

where $d$ is the ordinate of the highest intersection point $D$ between $\mu_{M_{1}}$ and $\mu_{M_{2}}$ (see Figure 3 ).

To compare $M_{2}$ and $M_{1}$, we need both values of $V\left(M_{1} \geq\right.$ $\left.M_{2}\right)$ and $V\left(M_{2} \geq M_{1}\right)$.

Step 3. The degree possibility for a convex fuzzy number to be greater than $k$ convex fuzzy numbers $M_{i}(i=1,2, \ldots, k)$ can be defined by

$$
\begin{gathered}
V\left(M \geq M_{1}, M_{2}, \ldots, M_{k}\right) \\
\quad=V\left[\left(M \geq M_{1}\right),\left(M \geq M_{2}\right)\right] \text { and } \cdots \times, \\
\left(M \geq M_{k}\right)=\min V\left(M \geq M_{i}\right), \quad i=1,2,3, \ldots, k .
\end{gathered}
$$

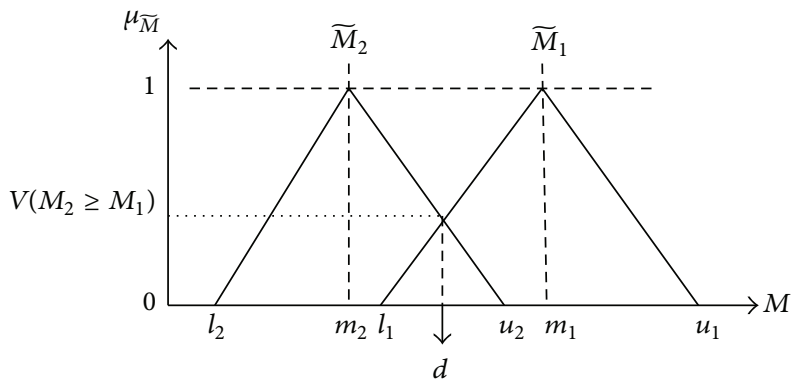

Figure 3: The intersection between $\mu_{1}$ and $\mu_{2}$.

Assume that

$$
d^{\prime}\left(A_{i}\right)=\min V\left(S_{i} \geq S_{k}\right) .
$$

For $k=1,2, \ldots, n ; k \neq i$. Then the weight vector is given by

$$
W^{\prime}=\left(d^{\prime}\left(A_{1}\right), d^{\prime}\left(A_{2}\right), \ldots, d^{\prime}\left(A_{n}\right)\right)^{T},
$$

where $A_{i}(i=1,2, \ldots, n)$ are $n$ elements.

Step 4. Via normalization, the normalized weight vectors are

$$
W=\left(d\left(A_{1}\right), d\left(A_{2}\right), \ldots, d\left(A_{n}\right)\right)^{T},
$$

where $W$ is a nonfuzzy number.

The analytic network process (ANP) is a comprehensive decision-making technique that captures the outcome of the dependence and feedback within and between the clusters of elements $[9,43]$. As indicated that human judgment about preferences are often unclear and hard to estimate by exact numerical values, again fuzzy logic is necessary for handing problems characterized by vagueness and imprecision. Therefore human judgments, which are unclear, simultaneously address the issue of combining both fuzzy set theory and ANP for sports centre performance evaluation model assessment. The steps for FANP calculation process can be given as follows [44].

After the previous stage which utilizes DEMATEL to analyze the mutual influential causality of the evaluation dimensions and setting up networked level evaluation structure is done, now current stage, FANP questionnaire is developed based on the previous stage. The FANP model of sports centre is defined in the following steps.

Step 1. Structure the FANP model hierarchically.

Step 2. Determine the local weights of the six factors and evaluation indicators by using pairwise comparison matrices (assume that there is no dependence among the five factors). The fuzzy scale regarding relative importance to calculate the relative weights is presented in Table 3 . This scale will be utilized in Chang's fuzzy AHP method.

Step 3. Determine, with fuzzy scale (Table 3), the innerdependence matrix of each main factor with respect to the other 
TABLE 3: Membership function of linguistic scale.

\begin{tabular}{lccc}
\hline $\begin{array}{l}\text { Fuzzy } \\
\text { number }\end{array}$ & Linguistic scale & $\begin{array}{c}\text { Triangular } \\
\text { fuzzy scale }\end{array}$ & $\begin{array}{c}\text { Inverse of triangular } \\
\text { fuzzy scale }\end{array}$ \\
\hline$\widetilde{1}$ & Equal & $(1,1,1)$ & $(1,1,1)$ \\
$\widetilde{2}$ & Weak advantage & $(1,2,3)$ & $(1 / 3,1 / 2,1)$ \\
$\widetilde{3}$ & Not bad & $(2,3,4)$ & $(1 / 4,1 / 3,1 / 2)$ \\
$\widetilde{4}$ & Preferable & $(3,4,5)$ & $(1 / 5,1 / 4,1 / 3)$ \\
$\widetilde{5}$ & Good & $(4,5,6)$ & $(1 / 6,1 / 5,1 / 4)$ \\
$\widetilde{6}$ & Fairly good & $(5,6,7)$ & $(1 / 7,1 / 6,1 / 5)$ \\
$\widetilde{7}$ & Very good & $(6,7,8)$ & $(1 / 8,1 / 7,1 / 6)$ \\
$\widetilde{8}$ & Absolute & $(7,8,9)$ & $(1 / 9,1 / 8,1 / 7)$ \\
$\widetilde{9}$ & Perfect & $(8,9,10)$ & $(1 / 10,1 / 9,1 / 8)$ \\
\hline
\end{tabular}

main factors. This innerdependence matrix is multiplied with the local weights of the five factors, determined in the previous step, to measure the interdependent weights of the six factors.

Step 4. Compute the global weights for the evaluation indicators. The global weights of evaluation criteria are calculated by multiplying local weight of the evaluation indicators with the interdependent weights of the factors to which it belongs.

\section{An Empirical Study}

The aim of this study is to evaluate the performance of Taipei's sports centres by using hybrid fuzzy MCDM. The study employs six-dimensions as the framework for establishing its performance evaluation indices, while FAHP/FANP is introduced within this framework to obtain the indices' weights. (We adopted the DEMATEL to address the complex and interdependent relationships among the variables and thereby construct a relation structure among the measurement factors for evaluation purposes.) The study's comprehensive analysis is illustrated in the steps described below.

Step 1 (constructing an evaluation framework). Using the literature review and experts' suggestions, an evaluation framework is established, as shown in Figure 2.

Step 2 (constructing the relationships among six-dimensions by DEMATEL). We asked 12 experts to indicate the critical level of relationships for sports centre measurement dimensions based on their experience. Summarizing their responses, we derive the average initial direct-relation $6 \times 6$ matrices A through pairwise comparisons based on (1) as follows:

$$
\mathbf{A}=\left[\begin{array}{llllll}
0.000 & 2.000 & 1.462 & 2.231 & 1.385 & 2.000 \\
2.077 & 0.000 & 1.154 & 1.769 & 1.615 & 2.308 \\
2.308 & 1.231 & 0.000 & 2.077 & 0.769 & 2.462 \\
1.692 & 1.462 & 2.000 & 0.000 & 1.308 & 2.231 \\
1.308 & 1.308 & 1.077 & 1.077 & 0.000 & 1.846 \\
2.385 & 2.000 & 2.308 & 2.231 & 1.231 & 0.000
\end{array}\right]
$$

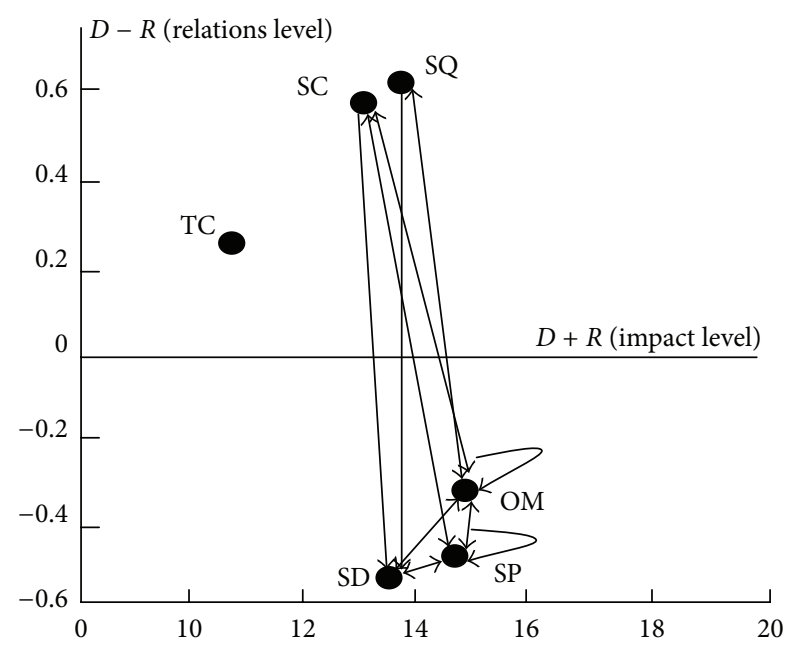

FIgURE 4: The digraph showing causal relations among sixdimensions.

Calculating the normalized initial direct-relation matrix D depicted as

$$
\begin{aligned}
\mathbf{D} & =\mathbf{A} \times \frac{1}{\max _{1 \leq i \leq 6} \sum_{j=1}^{6} a_{i j}} \\
& =\left[\begin{array}{lllllll}
0.000 & 0.197 & 0.144 & 0.220 & 0.136 & 0.197 \\
0.205 & 0.000 & 0.114 & 0.174 & 01.59 & 0.227 \\
0.227 & 0.121 & 0.000 & 0.205 & 0.076 & 0.242 \\
0.167 & 0.144 & 0.197 & 0.000 & 0.129 & 0.220 \\
0.129 & 0.129 & 0.106 & 0.106 & 0.000 & 0.182 \\
0.235 & 0.197 & 0.227 & 0.220 & 0.121 & 0.000
\end{array}\right] .
\end{aligned}
$$

We calculated matrix $\mathbf{T}$ by the following formula:

$$
\begin{aligned}
\mathbf{T} & =\mathbf{D}(\mathbf{I}-\mathbf{D})^{-1} \\
& =\left[\begin{array}{lllllll}
1.139 & 1.130 & 1.102 & 1.293 & 0.889 & 1.391 \\
1.292 & 0.952 & 1.064 & 1.243 & 0.896 & 1.392 \\
1.324 & 1.072 & 0.976 & 1.283 & 0.838 & 1.417 \\
1.250 & 1.061 & 1.112 & 1.080 & 0.857 & 1.370 \\
0.980 & 0.847 & 0.837 & 0.941 & 0.584 & 1.083 \\
1.451 & 1.229 & 1.263 & 1.412 & 0.956 & 1.355
\end{array}\right] .
\end{aligned}
$$

Table 4 depicts the direct and indirect effects of six perspectives (SP, SC, SQ, SD, TC, and OM). Finally, the threshold value is to compute the average of the elements in matrix $\mathbf{T}$, which are 1.121. The digraph of six perspectives is depicted in Figure 4.

Based on Table 4, the importance of the six perspectives can be prioritized as $\mathrm{OM}>\mathrm{SP}>\mathrm{SD}>\mathrm{SQ}>\mathrm{SC}>\mathrm{TC}$ based on $(D+R)$ values, where operations management is the most important criterion with the value of 15.674 , while traffic conditions is the least important criterion with the value of 10.291. In contrast to the importance, SQ, SC, TC, OM, SP, and $\mathrm{SD}$ are net receivers based on $(D-R)$ values.

Step 3 (application of FAHP in computing the local weights of the evaluation indices). Based on the hierarchical framework 
TABLE 4: The sum of influences on measurement dimensions.

\begin{tabular}{lccccccccc}
\hline & SP & SC & SQ & SD & TC & OM & $D_{i}$ & $D_{i}+R_{j}$ & $D_{i}-R_{j}$ \\
\hline SP & $\mathbf{1 . 1 3 9}$ & $\mathbf{1 . 1 3 0}$ & 1.102 & $\mathbf{1 . 2 9 3}$ & 0.889 & $\mathbf{1 . 3 9 1}$ & 6.944 & 14.379 & -0.492 \\
SC & $\mathbf{1 . 2 9 2}$ & 0.952 & 1.064 & $\mathbf{1 . 2 4 3}$ & 0.896 & $\mathbf{1 . 3 9 2}$ & 6.839 & 13.130 & 0.548 \\
SQ & $\mathbf{1 . 3 2 4}$ & 1.072 & 0.976 & $\mathbf{1 . 2 8 3}$ & 0.838 & $\mathbf{1 . 4 1 7}$ & 6.910 & 13.265 & 0.556 \\
TC & $\mathbf{1 . 2 5 0}$ & 1.061 & 1.112 & 1.080 & 0.857 & $\mathbf{1 . 3 7 0}$ & 6.729 & 13.981 & -0.523 \\
OM & 0.980 & 0.847 & 0.837 & 0.941 & 0.584 & 1.083 & 5.271 & Threshold value $=1.121$ \\
$R_{j}$ & 7.435 & 6.291 & 6.354 & 7.252 & 5.020 & 8.008 & & \\
\hline
\end{tabular}

Any value greater than Threshold value (1.121) is presented in bold.

of the study's evaluation criteria and subcriteria, a FAHP questionnaire using the geometric mean method (GMM) and TFNs was distributed to the 12 experts in order to solicit their professional opinions. In FAHP, the main criteria and subcriteria must first be compared using linguistic terms and their equivalent fuzzy numbers denoting comparison measures. The linguistic comparison terms and the equivalent fuzzy numbers used in this study are shown in Table 3.

The local weights of the criteria and subcriteria were determined by the FAHP. The pairwise comparisons were scored by the 12 participating experts. The fuzzy pairwise comparison matrices for the goal and the subcriteria are shown in Tables 5 and 6.

The values of the fuzzy synthetic extents relative to the goal were computed using (6) as follows:

$$
\begin{aligned}
S_{\mathrm{SP}} & =(7.147,8.574,11.797) \otimes(0.020,0.026,0.032) \\
& =(0.142,0.221,0.383), \\
S_{\mathrm{PC}} & =(5.901,7.530,9.974) \otimes(0.020,0.026,0.032) \\
& =(0.117,0.194,0.324), \\
S_{\mathrm{SQ}} & =(4.015,4.928,6.313) \otimes(0.020,0.026,0.032) \\
& =(0.080,0.127,0.205), \\
S_{\mathrm{SD}} & =(4.231,5.291,6.916) \otimes(0.020,0.026,0.032) \\
& =(0.084,0.136,0.224), \\
S_{\mathrm{TC}} & =(4.568,5.925,7.335) \otimes(0.020,0.026,0.032) \\
& =(0.091,0.153,0.238), \\
S_{\mathrm{OM}} & =(4.952,6.558,8.000) \otimes(0.020,0.026,0.032) \\
& =(0.098,0.169,0.260) .
\end{aligned}
$$

The synthetic values obtained were compared using (11), and the priority weights were then calculated, as shown in Table 7.

The weights vector is $W_{\text {goal }}^{\prime}=(1,0.871,0.401,0.494$, $0.585,0.694)^{T}$. After the normalization, the normalized weight vector relative to the goal is $W_{\text {goal }}=(0.247,0.215$, $0.099,0.122,0.145,0.172)^{T}$.

Step 4 (application of FANP in computing the weights of the six evaluation indices). In this step, the dependencies among the six perspectives are taken into account and interdependent weights of the six perspectives are computed. In order to determine the dependence among the six factors, the impact of each factor on every other factor using fuzzy pairwise comparisons is evaluated. Based on fuzzy pairwise comparison matrices, Table 8 presents the existing dependencies among the six factors.

Using the calculated relative importance weights, the dependence matrix of the six factors is constructed. Interdependent weights of the six factors are computed by multiplying the dependence matrix of the six factors with the local weights of the six factors obtained in the previous step. The interdependent weights of the six factors are computed in the following part:

$$
\begin{aligned}
{\left[\begin{array}{l}
\mathrm{SP} \\
\mathrm{SC} \\
\mathrm{SQ} \\
\mathrm{SD} \\
\mathrm{TC} \\
\mathrm{OM}
\end{array}\right]=} & {\left[\begin{array}{llllll}
1.000 & 0.437 & 0.553 & 0.674 & 0.000 & 0.396 \\
0.473 & 1.000 & 0.000 & 0.000 & 0.000 & 0.328 \\
0.067 & 0.000 & 1.000 & 0.000 & 0.000 & 0.145 \\
0.000 & 0.311 & 0.309 & 1.000 & 0.000 & 0.131 \\
0.000 & 0.000 & 0.000 & 0.000 & 1.000 & 0.000 \\
0.460 & 0.252 & 0.138 & 0.326 & 0.000 & 1.000
\end{array}\right] } \\
& \times\left[\begin{array}{l}
0.247 \\
0.215 \\
0.099 \\
0.122 \\
0.145 \\
0.172
\end{array}\right]=\left[\begin{array}{l}
0.294 \\
0.209 \\
0.076 \\
0.130 \\
0.078 \\
0.212
\end{array}\right] .
\end{aligned}
$$

As shown above, the results are significantly different from when the interdependent weights and dependencies are not taken into account. The final results change from 0.247 to $0.294,0.215$ to $0.209,0.099$ to $0.076,0.122$ to $0.130,0.145$ to 0.078 , and 0.172 to 0.212 for the priority values of factors SP, SC, SQ, SD, TC, and OM, respectively.

Step 5. In this step, the overall weights of the evaluation indices are calculated by multiplying the interdependent weights of six factors found in previous step with the local weights of evaluation indices obtained in Step 2. The overall weights have indicated for each indicator in Table 9.

The results show that the critical order for the sixdimensions of the sports centre evaluation is "SP: service prices (0.294)," "SC: site conditions (0.209)," "SQ: staff qualifies (0.076)," "SD: sport products (0.130)," "TC: traffic conditions (0.078)," and "OM: operations management (0.212)." 
TABLE 5: Fuzzy pairwise comparison matrix of six criteria with respect to the goal.

\begin{tabular}{lcccccc}
\hline & SP & SC & SQ & SD & TC & OM \\
\hline SP & $(1,1,1)$ & $(0.95,1.178,1.742)$ & $(1.644,2.074,2.898)$ & $(1.165,1.484,2.207)$ & $(1.328,1.567,2.229)$ & $(1.057,1.271,1.720)$ \\
BC & $(0.574,0.849,1.050)$ & $(1,1,1)$ & $(1.366,1.831,2.549)$ & $(1.616,2.078,2.853)$ & $(0.844,1.134,1.595)$ & $(0.500,0.638,0.927)$ \\
SQ & $(0.345,0.482,0.608)$ & $(0.392,0.546,0.732)$ & $(1,1,1)$ & $(1.179,1.565,2.166)$ & $(0.515,0.635,0.862)$ & $(0.583,0.700,0.945)$ \\
SD & $(0.453,0.674,0.858)$ & $(0.351,0.481,0.619)$ & $(0.462,0.639,0.848)$ & $(1,1,1)$ & $(0.961,1.200,1.693)$ & $(1.005,1.296,1.898)$ \\
TC & $(0.449,0.638,0.753)$ & $(0.627,0.882,1.184)$ & $(1.160,1.575,1.944)$ & $(0.591,0.833,1.041)$ & $(1,1,1)$ & $(0.742,0.996,1.414)$ \\
OM & $(0.581,0.787,0.946)$ & $(1.078,1.568,1.998)$ & $(1.058,1.428,1.714)$ & $(0.527,0.771,0.995)$ & $(0.707,1.004,1.347)$ & $(1,1,1)$ \\
\hline
\end{tabular}

TABLE 6: Fuzzy pairwise comparison matrix of twenty-three subcriteria with respect to the criteria.

\begin{tabular}{|c|c|c|c|c|}
\hline SP & $\mathrm{SP}_{1}$ & $\mathrm{SP}_{2}$ & $\mathrm{SP}_{3}$ & $\mathrm{SP}_{4}$ \\
\hline $\mathrm{SP}_{1}$ & $(1,1,1)$ & $(0.565,0.683,0.924)$ & $(0.462,0.595,0.852)$ & $(1.070,1.367,2.053)$ \\
\hline $\mathrm{SP}_{2}$ & $(1.083,1.465,1.771)$ & $(1,1,1)$ & $(1.581,1.976,2.790)$ & $(1.532,2.086,3.024)$ \\
\hline $\mathrm{SP}_{3}$ & $(1.173,1.677,2.166)$ & $(0.358,0.506,0.633)$ & $(1,1,1)$ & $(1.860,2.414,3.353)$ \\
\hline $\mathrm{SP}_{4}$ & $(0.487,0.731,0.935)$ & $(0.331,0.479,0.653)$ & $(0.298,0.414,0.537)$ & $(1,1,1)$ \\
\hline SC & $\mathrm{SC}_{1}$ & $\mathrm{SC}_{2}$ & $\mathrm{SC}_{3}$ & $\mathrm{SC}_{4}$ \\
\hline $\mathrm{SC}_{1}$ & $(1,1,1)$ & $(0.595,0.750,1.102)$ & $(0.937,1.204,1.789)$ & $(0.671,0.808,1.139)$ \\
\hline $\mathrm{SC}_{2}$ & $(0.907,1.333,1.681)$ & $(1,1,1)$ & $(2.135,2.804,3.783)$ & $(1.211,1.521,2.390)$ \\
\hline $\mathrm{SC}_{3}$ & $(0.559,0.830,1.067)$ & $(0.264,0.357,0.468)$ & $(1,1,1)$ & $(0.431,0.536,0.737)$ \\
\hline $\mathrm{SC}_{4}$ & $(0.878,1.238,1.491)$ & $(0.418,0.657,0.826)$ & $(1.356,1.865,2.321)$ & $(1,1,1)$ \\
\hline SQ & $\mathrm{SQ}_{1}$ & $\mathrm{SQ}_{2}$ & $\mathrm{SQ}_{3}$ & \\
\hline $\mathrm{SQ}_{1}$ & $(1,1,1)$ & $(1.238,1.538,2.245)$ & $(0.801,0.943,1.390)$ & \\
\hline $\mathrm{SQ}_{2}$ & $(0.445,0.650,0.808)$ & $(1,1,1)$ & $(0.969,1.198,1.810)$ & \\
\hline $\mathrm{SQ}_{3}$ & $(0.720,1.060,1.249)$ & $(0.552,0.835,1.032)$ & $(1,1,1)$ & \\
\hline SD & $\mathrm{SD}_{1}$ & $\mathrm{SD}_{2}$ & $\mathrm{SD}_{3}$ & $\mathrm{SD}_{4}$ \\
\hline $\mathrm{SD}_{1}$ & $(1,1,1)$ & $(0.692,0.922,1.377)$ & $(1.929,2.627,3.739)$ & $(1.845,2.523,3.527)$ \\
\hline $\mathrm{SD}_{2}$ & $(0.726,1.084,1.445)$ & $(1,1,1)$ & $(1.354,1.895,2.804)$ & $(1.055,1.466,2.118)$ \\
\hline $\mathrm{SD}_{3}$ & $(0.267,0.381,0.518)$ & $(0.357,0.528,0.739)$ & $(1,1,1)$ & $(0.704,0.979,1.458)$ \\
\hline $\mathrm{SD}_{4}$ & $(0.284,0.396,0.542)$ & $(0.472,0.682,0.948)$ & $(0.686,1.021,1.421)$ & $(1,1,1)$ \\
\hline TC & $\mathrm{TC}_{1}$ & $\mathrm{TC}_{2}$ & $\mathrm{TC}_{3}$ & $\mathrm{TC}_{4}$ \\
\hline $\mathrm{TC}_{1}$ & $(1,1,1)$ & $(1.292,1.537,2.508)$ & $(1.771,2.319,3.215)$ & $(1.249,1.604,2.357)$ \\
\hline $\mathrm{TC}_{2}$ & $(0.399,0.651,0.774)$ & $(1,1,1)$ & $(1.829,2.654,3.720)$ & $(1.277,1.636,2.486)$ \\
\hline $\mathrm{TC}_{3}$ & $(0.311,0.431,0.565)$ & $(0.269,0.377,0.547)$ & $(1,1,1)$ & $(0.742,0.877,1.347)$ \\
\hline $\mathrm{TC}_{4}$ & $(0.424,0.623,0.801)$ & $(0.402,0.611,0.783)$ & $(0.742,1.140,1.347)$ & $(1,1,1)$ \\
\hline $\mathrm{OM}$ & $\mathrm{OM}_{1}$ & $\mathrm{OM}_{2}$ & $\mathrm{OM}_{3}$ & $\mathrm{OM}_{4}$ \\
\hline $\mathrm{OM}_{1}$ & $(1,1,1)$ & $(0.838,1.088,1.581)$ & $(1.078,1.498,2.198)$ & $(0.694,0.835,1.333)$ \\
\hline $\mathrm{OM}_{2}$ & $(0.633,0.919,1.194)$ & $(1,1,1)$ & $(1.758,2.434,3.426)$ & $(1.421,1.766,2.740)$ \\
\hline $\mathrm{OM}_{3}$ & $(0.455,0.667,0.927)$ & $(0.292,0.411,0.569)$ & $(1,1,1)$ & $(0.534,0.646,0.948)$ \\
\hline $\mathrm{OM}_{4}$ & $(0.750,1.198,1.441)$ & $(0.365,0.566,0.704)$ & $(1.055,1.548,1.872)$ & $(1,1,1)$ \\
\hline
\end{tabular}

Table 9 shows the weights of the four "service prices perspective" indices $\left(\mathrm{SP}_{1}(0.189), \mathrm{SP}_{2}(0.434), \mathrm{SP}_{3}(0.367)\right.$, and $\left.\mathrm{SP}_{4}(0.010)\right)$, the four "site conditions perspective" indices $\left(\mathrm{SC}_{1}(0.212), \mathrm{SC}_{2}(0.481), \mathrm{SC}_{3}(0.010)\right.$, and $\left.\mathrm{SC}_{4}(0.296)\right)$, the three "staff qualifies perspective" indices $\left(\mathrm{SQ}_{1}(0.405)\right.$, $\mathrm{SQ}_{2}$ (0.304), and $\mathrm{SQ}_{3}(0.291)$ ), the four "sport products perspective" indices $\left(\mathrm{SD}_{1}(0.477), \mathrm{SD}_{2}(0.366), \mathrm{SD}_{3}(0.067)\right.$, and $\left.\mathrm{SD}_{4}(0.090)\right)$, the four "traffic conditions perspective" indices $\left(\mathrm{TC}_{1}\right.$ (0.448), $\mathrm{TC}_{2}(0.413), \mathrm{TC}_{3}(0.036)$, and $\mathrm{TC}_{4}$ $(0.103))$, and the four "operations management perspective" indices $\left(\mathrm{OM}_{1}(0.286), \mathrm{OM}_{2}(0.405), \mathrm{OM}_{3}(0.067)\right.$, and $\mathrm{OM}_{4}$ $(0.242))$.
Thus, the synthesis values (global weights) of the sports centre performance evaluation model under the 23 indicators are as follows: $\mathrm{SP}_{1}(0.047), \mathrm{SP}_{2}$ (0.107), $\mathrm{SP}_{3}$ (0.091), $\mathrm{SP}_{4}$ (0.002), $\mathrm{SC}_{1}$ (0.046), $\mathrm{SC}_{2}(0.104), \mathrm{SC}_{3}(0.002), \mathrm{SC}_{4}(0.064)$, $\mathrm{SQ}_{1}(0.040), \mathrm{SQ}_{2}(0.030), \mathrm{SQ}_{3}(0.029), \mathrm{SD}_{1}(0.058), \mathrm{SD}_{2}$ (0.045), $\mathrm{SD}_{3}(0.008), \mathrm{SD}_{4}(0.011), \mathrm{TC}_{1}(0.065), \mathrm{TC}_{2}(0.060)$, $\mathrm{TC}_{3}(0.005), \mathrm{TC}_{4}(0.015), \mathrm{OM}_{1}(0.049), \mathrm{OM}_{2}$ (0.070), $\mathrm{OM}_{3}$ (0.012), and $\mathrm{OM}_{4}(0.042)$.

Based on the overall weights listed in Table 9, the most and the least important indicators which can affect the sports centres performance evaluation model are "special discounts" and "ads and activities," respectively. As well as, 
TABLE 7: Values of $V\left(S_{j} \geq S_{i}\right)$ and min value.

\begin{tabular}{|c|c|c|c|c|c|}
\hline$V\left(S_{\mathrm{SP}} \geq S_{i}\right)$ & Value & $V\left(S_{\mathrm{SC}} \geq S_{i}\right)$ & Value & $V\left(S_{\mathrm{SQ}} \geq S_{i}\right)$ & Value \\
\hline$V\left(S_{\mathrm{SP}} \geq S_{\mathrm{SC}}\right)$ & 1 & $V\left(S_{\mathrm{SC}} \geq S_{\mathrm{SP}}\right)$ & 0.871 & $V\left(S_{\mathrm{SQ}} \geq S_{\mathrm{SP}}\right)$ & 0.401 \\
\hline$V\left(S_{\mathrm{SP}} \geq S_{\mathrm{SQ}}\right)$ & 1 & $V\left(S_{\mathrm{SC}} \geq S_{\mathrm{SQ}}\right)$ & 1 & $V\left(S_{\mathrm{SQ}} \geq S_{\mathrm{SC}}\right)$ & 0.567 \\
\hline$V\left(S_{\mathrm{SP}} \geq S_{\mathrm{SD}}\right)$ & 1 & $V\left(S_{\mathrm{SC}} \geq S_{\mathrm{SD}}\right)$ & 1 & $V\left(S_{\mathrm{SQ}} \geq S_{\mathrm{SD}}\right)$ & 0.928 \\
\hline$V\left(S_{\mathrm{SP}} \geq S_{\mathrm{TC}}\right)$ & 1 & $V\left(S_{\mathrm{SC}} \geq S_{\mathrm{TC}}\right)$ & 1 & $V\left(S_{\mathrm{SQ}} \geq S_{\mathrm{TC}}\right)$ & 0.816 \\
\hline$V\left(S_{\mathrm{SP}} \geq S_{\mathrm{OM}}\right)$ & 1 & $V\left(S_{\mathrm{SC}} \geq S_{\mathrm{OM}}\right)$ & 1 & $V\left(S_{\mathrm{SQ}} \geq S_{\mathrm{OM}}\right)$ & 0.717 \\
\hline min value & 1 & min value & 0.871 & min value & 0.401 \\
\hline$V\left(S_{\mathrm{SD}} \geq S_{i}\right)$ & Value & $V\left(S_{\mathrm{TC}} \geq S_{i}\right)$ & Value & $V\left(S_{\mathrm{OM}} \geq S_{i}\right)$ & Value \\
\hline$V\left(S_{\mathrm{SD}} \geq S_{\mathrm{SP}}\right)$ & 0.494 & $V\left(S_{\mathrm{TC}} \geq S_{\mathrm{SP}}\right)$ & 0.585 & $V\left(S_{\mathrm{OM}} \geq S_{\mathrm{SP}}\right)$ & 0.694 \\
\hline$V\left(S_{\mathrm{SD}} \geq S_{\mathrm{SC}}\right)$ & 0.650 & $V\left(S_{\mathrm{TC}} \geq S_{\mathrm{SC}}\right)$ & 0.745 & $V\left(S_{\mathrm{OM}} \geq S_{\mathrm{SC}}\right)$ & 0.850 \\
\hline$V\left(S_{\mathrm{SD}} \geq S_{\mathrm{SQ}}\right)$ & 1 & $V\left(S_{\mathrm{TC}} \geq S_{\mathrm{SQ}}\right)$ & 1 & $V\left(S_{\mathrm{OM}} \geq S_{\mathrm{SQ}}\right)$ & 1 \\
\hline$V\left(S_{\mathrm{SD}} \geq S_{\mathrm{TC}}\right)$ & 0.891 & $V\left(S_{\mathrm{TC}} \geq S_{\mathrm{SD}}\right)$ & 1 & $V\left(S_{\mathrm{OM}} \geq S_{\mathrm{SD}}\right)$ & 1 \\
\hline$V\left(S_{\mathrm{SD}} \geq S_{\mathrm{OM}}\right)$ & 0.794 & $V\left(S_{\mathrm{TC}} \geq S_{\mathrm{OM}}\right)$ & 0.895 & $V\left(S_{\mathrm{OM}} \geq S_{\mathrm{TC}}\right)$ & 1 \\
\hline min value & 0.494 & min value & 0.585 & min value & 0.694 \\
\hline
\end{tabular}

TABLE 8: The innerdependence matrix of the factors with respect to six main criteria.

\begin{tabular}{|c|c|c|c|c|c|}
\hline \multicolumn{6}{|c|}{ The innerdependence matrix of the factors with respect to "SP" } \\
\hline & SC & SQ & $\mathrm{OM}$ & & Local weights \\
\hline SC & $(1,1,1)$ & $(1.831,2.521,3.369)$ & $(0.485,0.613,0.879)$ & & 0.473 \\
\hline SQ & $(0.297,0.397,0.546)$ & $(1,1,1)$ & $(0.589,0.707,0.953)$ & & 0.067 \\
\hline $\mathrm{OM}$ & $(1.137,1.631,2.062)$ & $(1.050,1.415,1.699)$ & $(1,1,1)$ & & 0.460 \\
\hline \multicolumn{6}{|c|}{ The innerdependence matrix of the factors with respect to "SC" } \\
\hline & SP & SD & $\mathrm{OM}$ & & Local weights \\
\hline SP & $(1,1,1)$ & $(1.354,1.703,2.635)$ & $(0.818,0.979,1.324)$ & & 0.437 \\
\hline SD & $(0.380,0.587,0.739)$ & $(1,1,1)$ & $(1.060,1.337,1.940)$ & & 0.311 \\
\hline $\mathrm{OM}$ & $(0.755,1.022,1.222)$ & $(0.515,0.748,0.943)$ & $(1,1,1)$ & & 0.252 \\
\hline \multicolumn{6}{|c|}{ The innerdependence matrix of the factors with respect to "SQ" } \\
\hline & SP & SD & $\mathrm{OM}$ & & Local weights \\
\hline SP & $(1,1,1)$ & $(1.165,1.484,2.207)$ & $(1.336,1.624,2.203)$ & & 0.553 \\
\hline SD & $(0.453,0.674,0.858)$ & $(1,1,1)$ & $(0.953,1.191,1.799)$ & & 0.309 \\
\hline $\mathrm{OM}$ & $(0.454,0.616,0.749)$ & $(0.556,0.839,1.050)$ & $(1,1,1)$ & & 0.138 \\
\hline \multicolumn{6}{|c|}{ The innerdependence matrix of the factors with respect to "SD" } \\
\hline & SP & $\mathrm{OM}$ & & & Local weights \\
\hline SP & $(1,1,1)$ & $(1.035,1.226,1.625)$ & & & 0.674 \\
\hline $\mathrm{OM}$ & $(0.615,0.815,0.966)$ & $(1,1,1)$ & & & 0.326 \\
\hline \multicolumn{6}{|c|}{ The innerdependence matrix of the factors with respect to "OM" } \\
\hline & SP & SC & SQ & SD & Local weights \\
\hline SP & $(1,1,1)$ & $(0.932,1.142,1.652)$ & $(1.829,2.347,3.153)$ & $(1.165,1.552,2.256)$ & 0.396 \\
\hline SC & $(0.605,0.876,1.073)$ & $(1,1,1)$ & $(1.324,1.791,2.506)$ & $(1.532,2.015,2.790)$ & 0.328 \\
\hline SQ & $(0.317,0.426,0.547)$ & $(0.399,0.559,0.755)$ & $(1,1,1)$ & $(1.179,1.565,2.166)$ & 0.145 \\
\hline SD & $(0.443,0.644,0.858)$ & $(0.358,0.496,0.653)$ & $(0.462,0.639,0.848)$ & $(1,1,1)$ & 0.131 \\
\hline
\end{tabular}

under the services prices subcriteria, the most important indicator, out of the four indicators, is "special discounts," with a weight of 0.107 . This means that the major benefits concern for the sports centre managers in selecting and evaluating the best special discounts strategy is to have a high profit of the activities. Furthermore, under the site conditions subcriteria, "professional facilities" with a priority of 0.104 are the most important indicators. This indicator that sports centres should expend more effort on their professional facilities update for creating revenue growth and maintaining customer loyalty. They should also provide more facilities functions and fun features on their sports centres. Besides, under the staff quality subcriteria, "communication and coordination" with a weight of 0.040 is the most significant indicator. This implies that communication and coordination is more important than other evaluation indicators in order to improve service quality of sports centre staff with customers. Under the sport products subcriteria, "sports types" with 
TABLE 9: Weights of the main evaluation indices by FAHP.

\begin{tabular}{|c|c|c|c|c|}
\hline Criteria & Weights & Subcriteria & Local weights & Global weights \\
\hline \multirow{4}{*}{ SP } & \multirow{4}{*}{$0.294(1)$} & $\mathrm{SP}_{1}$ & 0.189 & $0.047(10)$ \\
\hline & & $\mathrm{SP}_{2}$ & 0.434 & $0.107(1)$ \\
\hline & & $\mathrm{SP}_{3}$ & 0.367 & $0.091(3)$ \\
\hline & & $\mathrm{SP}_{4}$ & 0.010 & $0.002(22-23)$ \\
\hline \multirow{4}{*}{ SC } & \multirow{4}{*}{$0.209(3)$} & $\mathrm{SC}_{1}$ & 0.212 & $0.046(11)$ \\
\hline & & $\mathrm{SC}_{2}$ & 0.481 & $0.104(2)$ \\
\hline & & $\mathrm{SC}_{3}$ & 0.010 & $0.002(22-23)$ \\
\hline & & $\mathrm{SC}_{4}$ & 0.296 & $0.064(6)$ \\
\hline \multirow{3}{*}{ SQ } & \multirow{3}{*}{$0.076(6)$} & $\mathrm{SQ}_{1}$ & 0.405 & $0.040(14)$ \\
\hline & & $\mathrm{SQ}_{2}$ & 0.304 & $0.030(15)$ \\
\hline & & $\mathrm{SQ}_{3}$ & 0.291 & $0.029(16)$ \\
\hline \multirow{4}{*}{ SD } & \multirow{4}{*}{$0.130(4)$} & $\mathrm{SD}_{1}$ & 0.477 & $0.058(8)$ \\
\hline & & $\mathrm{SD}_{2}$ & 0.366 & $0.045(12)$ \\
\hline & & $\mathrm{SD}_{3}$ & 0.067 & $0.008(20)$ \\
\hline & & $\mathrm{SD}_{4}$ & 0.090 & $0.011(19)$ \\
\hline \multirow{4}{*}{ TC } & \multirow{4}{*}{$0.078(5)$} & $\mathrm{TC}_{1}$ & 0.448 & $0.065(5)$ \\
\hline & & $\mathrm{TC}_{2}$ & 0.413 & $0.060(7)$ \\
\hline & & $\mathrm{TC}_{3}$ & 0.036 & $0.005(21)$ \\
\hline & & $\mathrm{TC}_{4}$ & 0.103 & $0.015(17)$ \\
\hline \multirow{4}{*}{$\mathrm{OM}$} & \multirow{4}{*}{$0.212(2)$} & $\mathrm{OM}_{1}$ & 0.286 & $0.049(9)$ \\
\hline & & $\mathrm{OM}_{2}$ & 0.405 & $0.070(4)$ \\
\hline & & $\mathrm{OM}_{3}$ & 0.067 & $0.012(18)$ \\
\hline & & $\mathrm{OM}_{4}$ & 0.242 & $0.042(13)$ \\
\hline
\end{tabular}

Note: () denotes ranking order.

a priority of 0.058 is the most important indicators. The sports centres should also provide various sports types for customer choice. And then, under the traffic conditions subcriteria, "transport facilities" with a weight of 0.065 is the most significant indicator. This implies that transport facilities are more important than other evaluation indicators in order to provide customers' convenient. Finally, under the operations management subcriteria, "safety maintenance" with a priority of 0.070 is the most important indicator. This implies that sports centre have to provide more complete safety maintenance with customer's safety.

\section{Conclusions}

This study adopted the quantitative evaluation indices developed by the Taipei city sports centres to establish a fuzzy network hierarchical structure. Expert opinions were compiled using the FANP to perform a weight analysis on the evaluation indices. We then conducted an empirical analysis using the FANP. The important research conclusions, practical management implications, limitations, and suggestions for future research are summarized as follows.

This study conducted a performance analysis on Taipei's sports centres through the DEMATEL and FANP approach using six dimensions. The empirical findings can be summarised as follows. First, after integrating all the relevant literature reviews and expert opinions, 23 indices were identified as being relevant to the centre's performance in terms of the six-dimensions. Second, the empirical results of the FANP provided the order of importance for the six centre performance dimensions: service prices, site conditions, operations management, traffic conditions, sport products, and staff quality. Therefore, the service prices, site conditions, and operations management are the three most important factors in any evaluation of the performance of sports centre managers. Third, the empirical results of the FANP provided the order of importance for the 23 sports centre performance evaluation indices: special discounts, professional facilities, membership benefits, safety maintenance, transport facilities, facilities safety, parking space, sports types, management systems, and charging methods. Thus, the special discounts, professional facilities, membership benefits, safety maintenance, and transport facilities are the five most important evaluation indices in any evaluation of the performance of sports centre managers. Thus, this study's use of FANP and statistics has provided sports centre managers with a reliable decision-making reference with which they can formulate a business strategy that optimally meets their customer's expectations.

The empirical results indicate that "service prices" (0.247) has the highest value among the model's six main criteria, while "site conditions" $(0.215)$ has the second highest value, "operations management," (0.172) the third highest, and "staff quality," (0.099) the least.

Although our study contributes to the evaluation of sports centre performance and helps sports centre managers create 
the best business strategies, it still has limitations. Previous research has found that staff quality is important, while our results indicate that staff quality is the least important indicator; thus, our results cannot be generalised widely. Moreover, although the study's criteria and features were edited according to suggestions from academics and sports centre managers in Taipei, we may have overlooked some important criteria and features. However, sports management practitioners may still adopt our analytic approach to improve their centre's performance.

We hope that our sports centre performance evaluation model will help sports centre managers and other decision makers formulate ideal business strategies. A future study could utilise the DEMATEL to examine the interactive and feedback relationships among the subcriteria of the six main perspectives and thus enrich the research on sports centres.

\section{Acknowledgments}

The authors are grateful to the editor Kim-Hua Tan and three anonymous referees for their valuable comments and suggestions which helped in improving the quality of this paper.

\section{References}

[1] C.-R. Wu, C.-T. Lin, and P.-H. Tsai, "Evaluating business performance of wealth management banks," European Journal of Operational Research, vol. 207, no. 2, pp. 971-979, 2010.

[2] C.-R. Wu, C.-T. Lin, and P.-H. Tsai, "Financial service sector performance measurement model: AHP sensitivity analysis and balanced scorecard approach," The Service Industries Journal, vol. 31, no. 5, pp. 695-711, 2011.

[3] H.-Y. Wu, Y.-K. Lin, and C.-H. Chang, "Performance evaluation of extension education centers in universities based on the balanced scorecard," Evaluation and Program Planning, vol. 34, no. 1, pp. 37-50, 2011.

[4] G. Bruno, E. Esposito, A. Genovese, and R. Passaro, "AHP-based approaches for supplier evaluation: problems and perspectives," Journal of Purchasing and Supply Management, vol. 18, pp. 159$172,2012$.

[5] T. Chen and K.-S. Sun, "Exploring the strategy to improve senior citizens' participations on recreational sports," Knowledge-Based Systems, vol. 26, pp. 86-92, 2012.

[6] M. Salimi, M. Soltanhosseini, D. Padash, and E. Khalili, "Prioritization of the factors effecting privatization in sport clubs: with AHP \& TOPSIS methods-emphasis in football," International Journal of Academic Research in Business and Social Sciences, vol. 2, pp. 102-114, 2012.

[7] A. V. Horenbeek and L. Pintelon, "Development of a maintenance performance measurement framework-using the analytic network process (ANP) for maintenance performance indicator selection," Omega, vol. 42, pp. 33-46, 2014.

[8] T. L. Saaty, The Analytic Hierarchy Process, McGraw-Hill, New York, NY, USA, 1980.

[9] C.-R. Wu, C.-T. Lin, and P.-H. Tsai, "Analysing alternatives in financial services for wealth management banks: the analytic network process and the balanced scorecard approach," IMA Journal Management Mathematics, vol. 20, no. 3, pp. 303-321, 2009.
[10] S. H. Zolfani, I. S. Chen, N. Rezaeiniya, and J. Tamošaitienè, "A hybrid MCDM model encompassing AHP and COPRAS-G methods for selecting company supplier in Iran," Technological and Economic Development of Economy, vol. 18, pp. 529-543, 2012.

[11] H.-P. Fu, K.-K. Chu, P. Chao, H.-H. Lee, and Y.-C. Liao, "Using fuzzy AHP and VIKOR for benchmarking analysis in the hotel industry," The Service Industries Journal, vol. 31, no. 14, pp. 2373 2389, 2011.

[12] L. Z. Lin, L. C. Huang, and H. R. Yeh, "Fuzzy group decisionmaking for service innovations in quality function deployment," Group Decision and Negotiation, vol. 21, pp. 495-517, 2012.

[13] C. Y. Lin and Y. C. Shiue, "An application of AHP and sensitivity analysis for measuring the best strategy of reverse logistics: a case study of photovoltaic industry chain," Journal of Testing and Evaluation, vol. 41, no. 3, 12 pages, 2013.

[14] A. Baležentisb, T. Baležentisb, and A. Misiunas, "Anintegrated assessment of Lithuanian economic sectors based on financial ratios and fuzzy MCDM methods," Technological and Economic Development of Economy, vol. 18, pp. 34-53, 2012.

[15] J.-K. Chen, "The assessment of vision re-creation indices for the automotive industry in Taiwan: a hybrid fuzzy model approach," Measurement, vol. 45, no. 5, pp. 909-917, 2012.

[16] N. Yalcin, A. Bayrakdaroglu, and C. Kahraman, "Application of fuzzy multi-criteria decision making methods for financial performance evaluation of Turkish manufacturing industries," Expert Systems with Applications, vol. 39, no. 1, pp. 350-364, 2012.

[17] Z. Li, W. K. Wong, and C. K. Kwong, "An integrated model of material supplier selection and order allocation using fuzzy extended AHP and multiobjective programming," Mathematical Problems in Engineering, vol. 2013, Article ID 363718, 14 pages, 2013.

[18] A. Gabus and E. Fontela, World Problems, an Invitation to Further Thought within the Framework of DEMATEL, Battelle Geneva Research Centre, Geneva, Switzerland, 1972.

[19] H.-Y. Wu, J.-K. Chen, I.-S. Chen, and H.-H. Zhuo, "Ranking universities based on performance evaluation by a hybrid MCDM model," Measurement, vol. 45, no. 5, pp. 856-880, 2012.

[20] G. Caliskan, "Criteria in sport management," International Business Management, vol. 3, no. 2, pp. 22-31, 2009.

[21] H. D. Horch, "The German sport club and the Japanese firm," European Journal for Sport Management, vol. 3, pp. 21-34, 1996.

[22] H. D. Horch, "Self-destroying processes of sport clubs in Germany," European Journal for Sport Management, vol. 5, pp. 46-58, 1998.

[23] S. Lee and P. Walsh, "SWOT and AHP hybrid model for sport marketing outsourcing using a case of intercollegiate sport," Sport Management Review, vol. 14, no. 4, pp. 361-369, 2011.

[24] S. Lee and S. D. Ross, "Sport sponsorship decision making in a global market: an approach of Analytic Hierarchy Process (AHP)," Sport, Business and Management, vol. 2, pp. 156-168, 2012.

[25] Z. Sinuany-Stern, "Ranking of sports teams via the AHP," Journal of the Operational Research Society, vol. 39, no. 7, pp. 661-667, 1988.

[26] M. R. Lanoue and J. J. Revetta Jr., "An analytic hierarchy approach to major league baseball offensive performance ratings," Mathematical and Computer Modelling, vol. 17, no. 4-5, pp. 195-209, 1993. 
[27] M. Gou, "Modeling for athletic sports strategies based on fuzzy system," Advances in Intelligent and Soft Computing, vol. 62, pp. 447-455, 2009.

[28] S.-K. Liao and K.-L. Chang, "Select televised sportscasters for olympic games by analytic network process," Management Decision, vol. 47, no. 1, pp. 14-23, 2009.

[29] T. H. Chen, "Using hybrid MCDM model for enhancing the participation of teacher in recreational sports," Journal of Decision Systems, vol. 20, no. 1, pp. 33-49, 2011.

[30] T. Kaya and C. Kahraman, "Multicriteria renewable energy planning using an integrated fuzzy VIKOR \& AHP methodology: the case of Istanbul," Energy, vol. 35, no. 6, pp. 2517-2527, 2010.

[31] H. C. Rajput, A. S. Milani, and A. Labun, "Including time dependency and ANOVA in decision-making using the revised fuzzy AHP: a case study on wafer fabrication process selection," Applied Soft Computing Journal, vol. 11, no. 8, pp. 5099-5109, 2011.

[32] C.-H. Hsu, F.-K. Wang, and G.-H. Tzeng, "The best vendor selection for conducting the recycled material based on a hybrid MCDM model combining DANP with VIKOR," Resources, Conservation and Recycling, vol. 66, pp. 95-111, 2012.

[33] J. Rezaei and R. Ortt, "Multi-criteria supplier segmentation using a fuzzy preference relations based AHP," European Journal of Operational Research, vol. 225, pp. 75-84, 2013.

[34] G.-H. Tzeng, C.-H. Chiang, and C.-W. Li, "Evaluating intertwined effects in e-learning programs: a novel hybrid MCDM model based on factor analysis and DEMATEL," Expert Systems with Applications, vol. 32, no. 4, pp. 1028-1044, 2007.

[35] L. A. Zadeh, "Fuzzy sets," Information and Computation, vol. 8, pp. 338-353, 1965.

[36] H. J. Zimmermann, Fuzzy Set Theory and Its Applications, Kluwer Academic, Boston, Mass, USA, 2nd edition, 1991.

[37] C.-L. Yang, S.-P. Chuang, and R.-H. Huang, "Manufacturing evaluation system based on AHP/ANP approach for wafer fabricating industry," Expert Systems with Applications, vol. 36, no. 8, pp. 11369-11377, 2009.

[38] A. Görener, K. Toker, and K. Uluçay, "Application of combined SWOT and AHP: a case study for a manufacturing firm," Procedia-Social and Behavioral Sciences, vol. 58, pp. 1525-1534, 2012.

[39] L.-A. Vidal, F. Marle, and J.-C. Bocquet, "Using a delphi process and the Analytic Hierarchy Process (AHP) to evaluate the complexity of projects," Expert Systems with Applications, vol. 38, no. 5, pp. 5388-5405, 2011.

[40] N. Manteghi and M. J. H. Jahromi, "Propose a model to choose best project by AHP in distributed generation," Procedia Technology, vol. 1, pp. 481-484, 2012.

[41] D. Y. Chang, "Extent analysis and synthetic decision," Optimization Techniques and Applications, vol. 1, no. 1, p. 352, 1992.

[42] D.-Y. Chang, "Applications of the extent analysis method on fuzzy AHP," European Journal of Operational Research, vol. 95, no. 3, pp. 649-655, 1996.

[43] T. L. Saaty, Decision Making with Dependence and Feedback: The Analytic Network Process, RWS Publication, Pittsburgh, Pa, USA, 1996.

[44] M. M. Fouladgar, A. Yazdani-Chamzini, E. K. Zavadskas, and S. H. Haji Moini, "A new hybrid model for evaluating the working strategies: case study of construction company," Technological and Economic Development of Economy, vol. 18, pp. 164-188, 2012. 


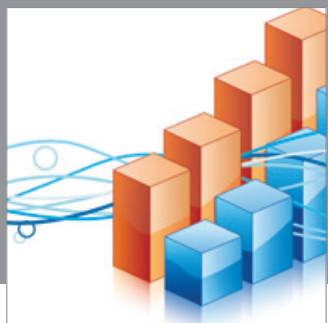

Advances in

Operations Research

mansans

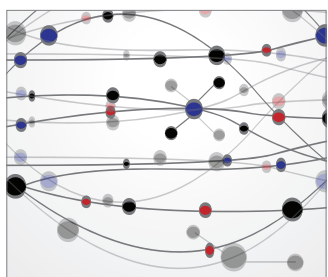

The Scientific World Journal
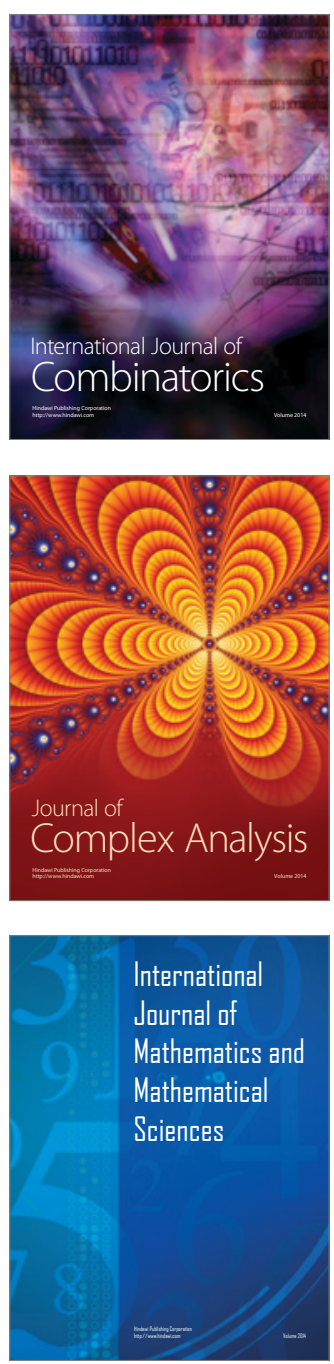
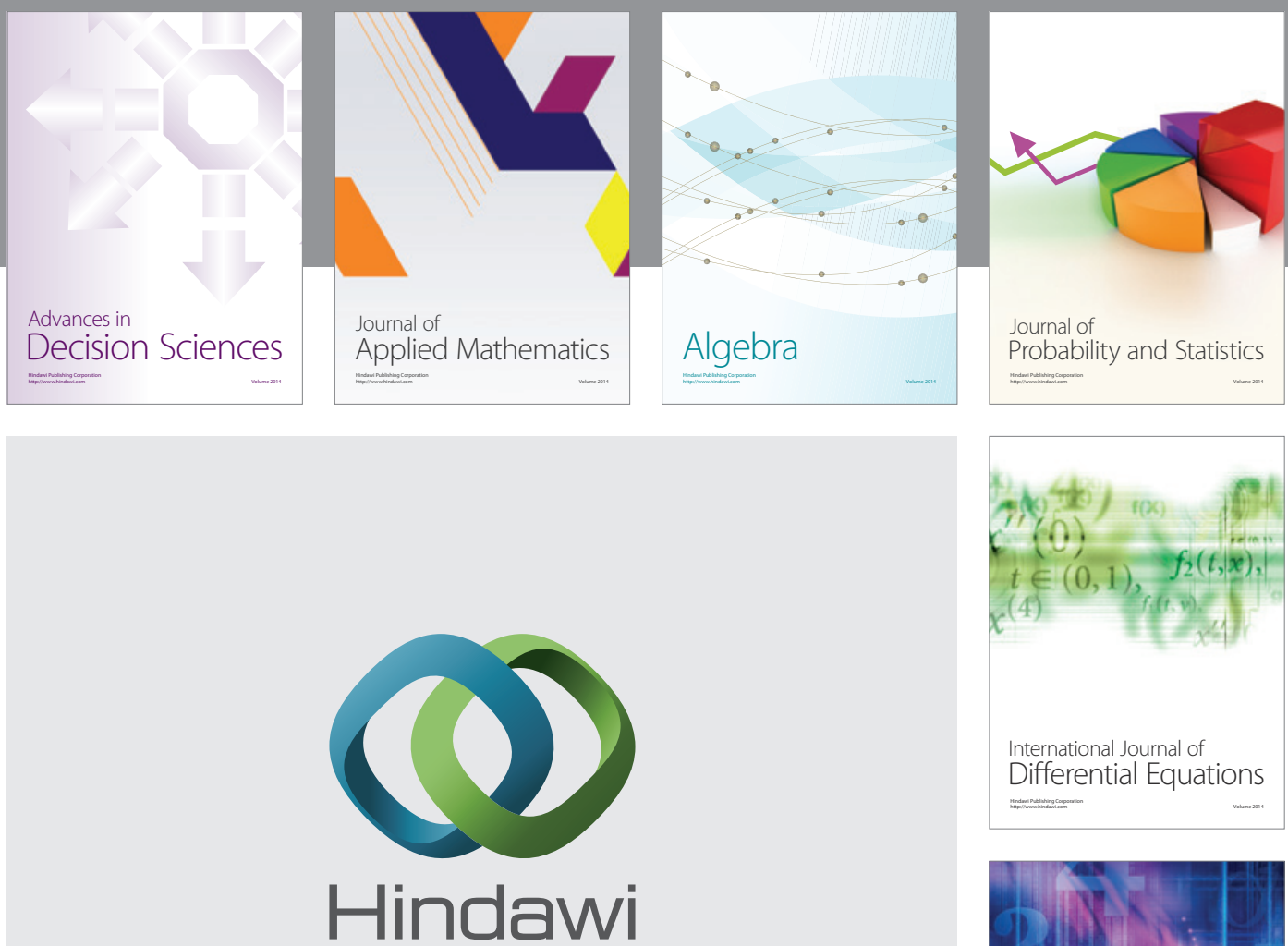

Submit your manuscripts at http://www.hindawi.com
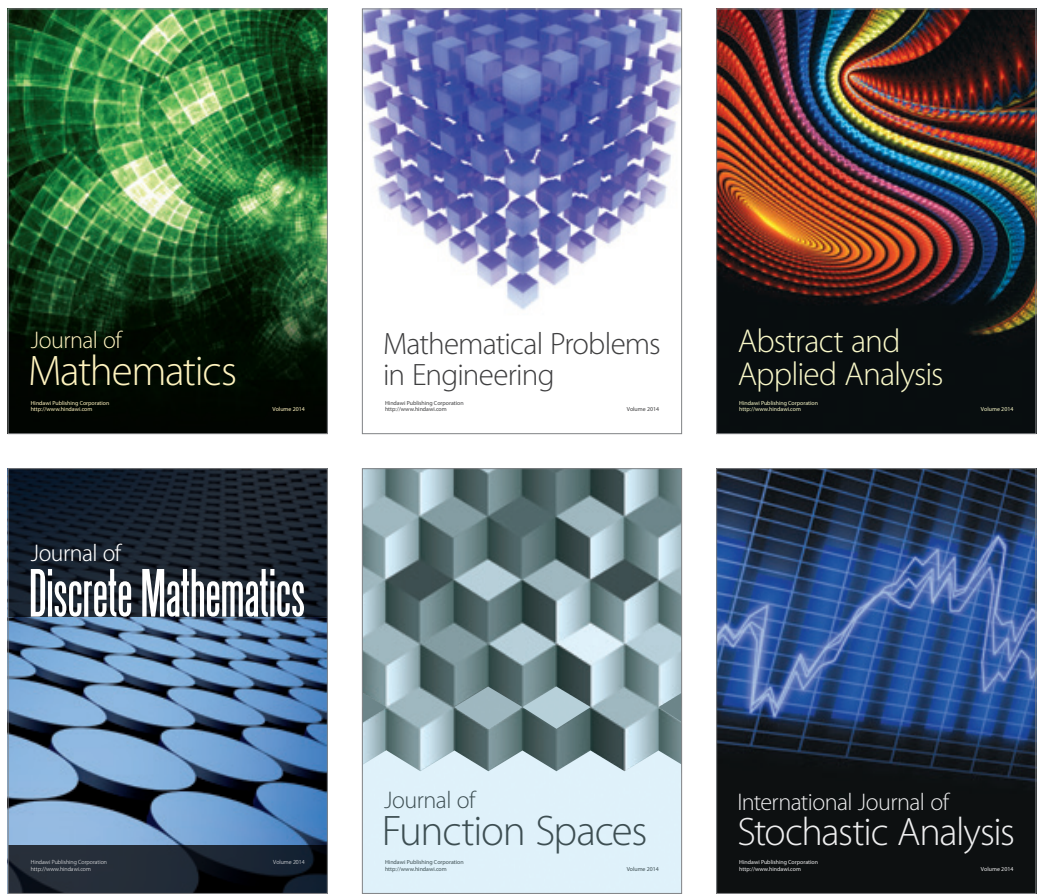

Journal of

Function Spaces

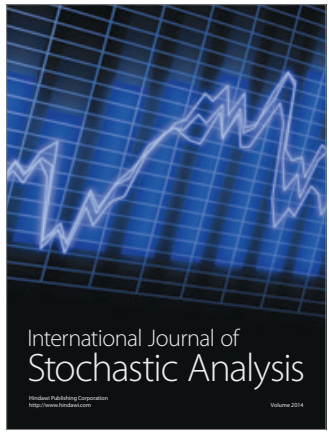

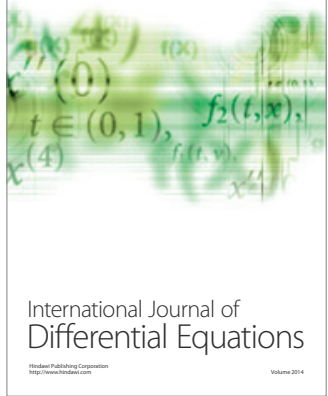
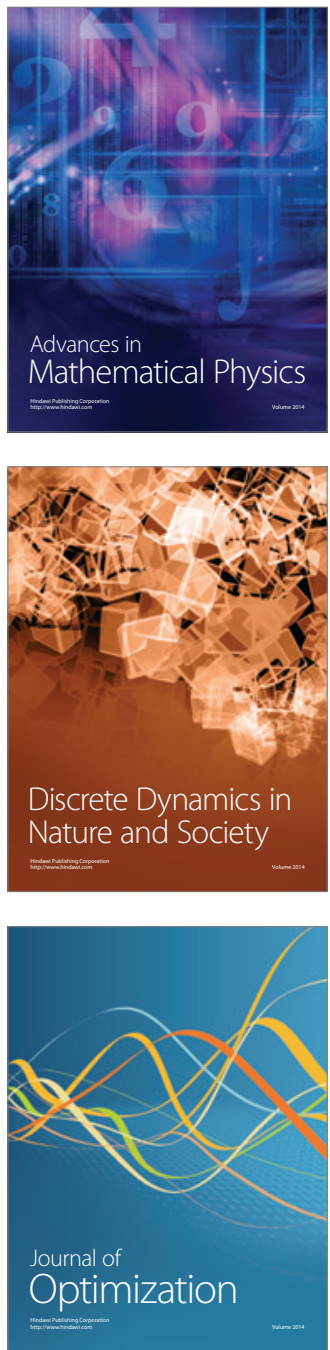